\title{
A Metal Stent in a Colostomy Obstruction
}

\author{
Nienke A. van Gils Jacqueline G.H.M. Cornelissen Adriaan C.I.T.L. Tan \\ Department of Hepatogastroenterology, Canisius Wilhelmina Hospital, Nijmegen, The Netherlands
}

Keywords

Colon · Colorectal cancer $\cdot$ Endoscopy

\section{Colocação de prótese metálica em estenose de colostomia}

\section{Palavras Chave}

Cólon · Carcinoma colo-retal $\cdot$ Endoscopia

We report a case where a metal stent was used to relieve a tumorous colostomy obstruction and the usage of a plaster cast to protect the stent from causing external symptoms.

A 50-year-old woman presented with vomiting, abdominal pain, and absent colostomy production. Two years before, she was diagnosed with sigmoid carcinoma (pT4N1M1 with peroperative omental metastasis), for which resection with adjuvant chemotherapy (oxaliplatin and capecitabine) was performed. Despite this, progression of disease was seen and HIPEC (adjuvant hyperther-

\section{KARGER}

E-Mail karger@karger.com www.karger.com/pjg
(C) 2018 Sociedade Portuguesa de Gastrenterologia Published by S. Karger AG, Basel

Karger

Open access

This article is licensed under the Creative Commons Attribution NonCommercial-NoDerivatives 4.0 International License (CC BYNC-ND) (http://www.karger.com/Services/OpenAccessLicense). Usage and distribution for commercial purposes as well as any distribution of modified material requires written permission. mic intraperitoneal chemotherapy) procedure was performed. Afterwards, she again started chemotherapy. A few months later, however, progression of disease was reported (by CT scan) and 12 cycles of palliative chemotherapy (irinotecan and bevacizumab) followed. She stopped therapy because of side effects.

On admission, distended bowel loops were seen on CT caused by stenosis of the colostomy due to tumor overgrowth. Endoscopy revealed a short segment of obstruction right after introduction through the colostomy. Given the poor prognosis and recent surgeries, a surgical approach was not possible. Therefore, a 6-cm uncovered 25$\mathrm{mm}$ WallFlex stent (Boston Scientific) was placed with good functional result. Two months later, tumor growth again led to obstruction of the colostomy. Then, a fully covered, proximal-release, $10-\mathrm{cm} 25-\mathrm{mm}$ WallFlex stent (Boston Scientific) stent was placed. From the beginning, the metal stent protruded around $1 \mathrm{~cm}$ from the colostomy (Fig. 1), causing pain and practical difficulties such as wearing clothes. A plaster cast was created to cover the colostomy and the stent causing less pain (Fig. 2). Six months later, the patient died due to progressive disease, without clinical evidence of re-obstruction of the colostomy. 


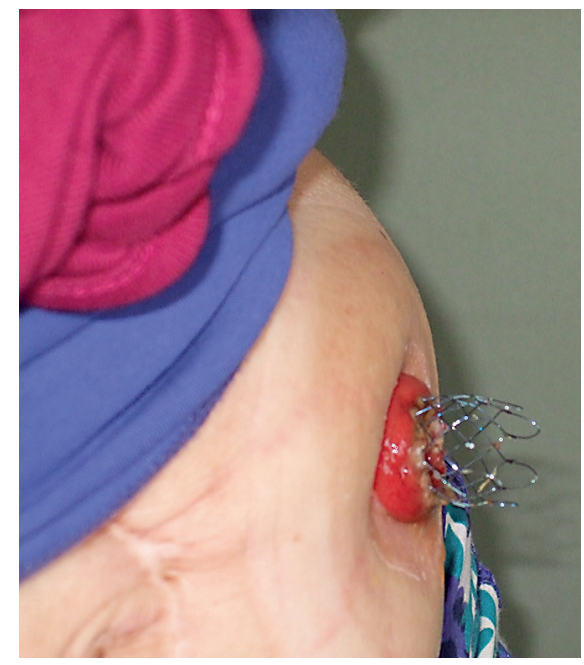

Fig. 1. Stent protruding from colostomy.

In case of malignant (re-)obstruction of a colostomy, metal stent placement can be a good alternative in patients with poor performance status and progressive disease if surgery is not an option. When the obstruction is just beneath the level of the colostomy, the metal stent has to be placed with its proximal phalange out of the colostomy. This creates difficulties in cleaning and wearing clothes. A previous case report [1] used a rather difficult method of fixing the stent to the skin. We created a plaster cast to overcome this problem. This simple yet elegant solution resulted in a good quality of life.

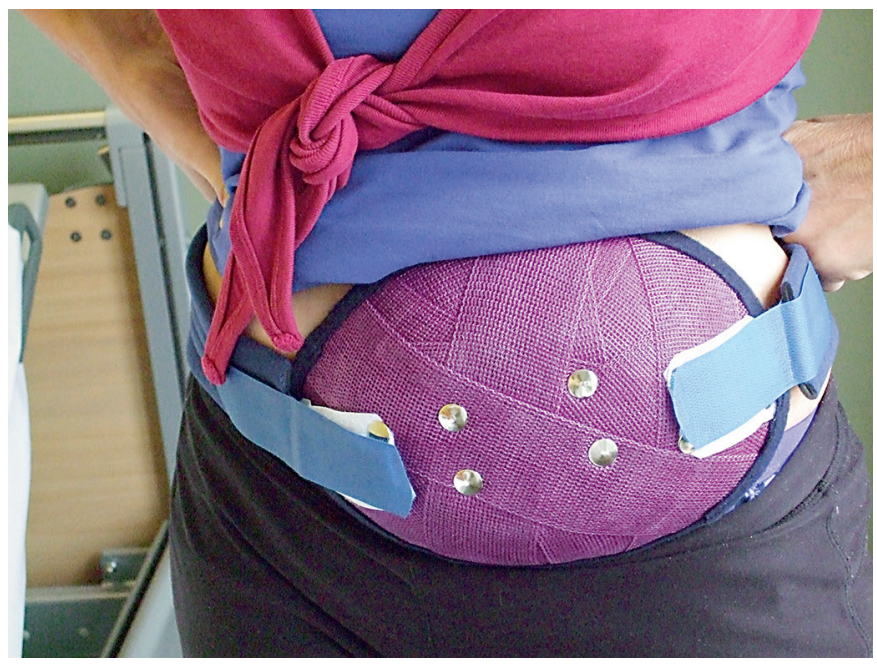

Fig. 2. Plaster cast protecting the stent.

\section{Statement of Ethics}

This study did not require informed consent or review/approval by the appropriate ethics committee.

\section{Disclosure Statement}

The authors have no conflicts of interest to declare.

\section{References}

1 Kim WH, Kwon CI, Kim JW, Lee C: Insertion of a SEMS for a stomal stenosis. Endoscopy 2012;44:E143-E144. 